\title{
A caixa fechada e o método científico
}

\author{
Edvaldo Sabadini * \\ sabadini@iqm.unicamp.br \\ Universidade Estadual de Campinas, Instituto de Química
}

\section{Informações do Artigo Resumo}

Histórico do Artigo

Criado em Julho de 2004

\section{Palavras-Chaves}

Método científico Experimento em ciência

Caixa fechada

Lei científica

Processo dedutivo

Interatividade

Jogo de adivinhação
Esta é uma proposta de atividade que envolve um exemplo lúdico da aplicação do método científico. Ela é baseada na descoberta da identidade de um objeto conhecido apenas pelo professor, que se encontra dentro de uma caixa fechada. A caixa permanece intocada durante a atividade e, os alunos são estimulados a descobrir qual é o objeto que está no seu interior. O caminho para a descoberta passará por perguntas seqüenciais feitas pelos estudantes ao professor. Cada estudante poderá formular uma pergunta ou então trocar a pergunta por uma tentativa de resposta. $\mathrm{O}$ professor responderá apenas SIM ou NÃO. Obviamente a identificação do objeto que se encontra no interior da caixa vai se tornando mais provável, na medida que o número de respostas (positivas e negativas) vai aumentando. Como essa atividade permite uma grande interação entre os alunos e o professor, sugere-se que sua execução ocorra no primeiro dia de aula dos alunos ingressantes, para permitir uma efetiva integração logo no início das atividades acadêmicas. A correlação entre esta atividade e o método científico pode então ser explicitada pelo professor, citando exemplos como o desenvolvimento do modelo atômico, que evoluiu pela aplicação sistemática do método científico.

\section{Introdução}

Ao iniciar uma disciplina o professor depara-se com uma situação bastante comum, onde os alunos geralmente pensam na ciência como se tudo estivesse completamente explicado. $\mathrm{Na}$ verdade esta é uma visão da maioria das pessoas, evidenciada por Lewis e Randall, no prefácio do livro Thermodynamics [1]: ..... "a ciência é vista como uma magnifica catedral, na qual ficamos encantados ao visitá-la e, vendo apenas a perfeição do todo, fica a impressão de que ela é obra de uma atividade sobre-humana. Assim, não ficam explícitos o trabalho árduo dos operários, os andaimes utilizados e, principalmente, os erros cometidos".

De certa forma, ao iniciar uma disciplina, deseja-se que a construção de uma "catedral" de raciocínios e conhecimentos químicos seja iniciada na mente de cada um dos alunos. Os alunos precisam compreender que a ciência continua em desenvolvimento, não é absoluta e que foi também construída, com erros e aperfeiçoamentos, com hipóteses e testes que a reforçam ou refutam.

Muitas vezes o raciocínio que levou a uma descoberta, a discussão sobre as várias hipóteses envolvidas e, experimentos que permitiram aperfeiçoar um modelo para explicá-la, despertam grandemente o interesse dos alunos pelo assunto, e permitem também o desenvolvimento do raciocínio lógico. É interessante mostrar aos estudantes que a ciência se desenvolve usando o método científico 
que, resumidamente, é definido como um processo sistemático de investigação científica que pode ser dividido em algumas etapas [2]. Essas etapas são:

1. A coleção de dados, obtidos pela observação e por medidas.

2. A formulação de uma Lei Científica, que sumariza as observações.

3. O desenvolvimento de hipóteses, a partir das quais pode-se planejar experimentos.

4. Se os experimentos dão suporte às hipóteses, então pode ser formulada uma Teoria, cuja validade dependerá de futuros experimentos.

A presente proposta, que se baseia na apresentação de alguns aspectos do método científico de uma forma lúdica, acaba atingindo vários objetivos. Um deles permite a maior integração entre os alunos e, entre os alunos e o docente. Um outro objetivo mostra aos alunos o potencial dedutivo da mente humana, que pode ser usado em uma brincadeira de adivinhação ou em ciência.

Alguns paralelos das etapas envolvidas no método científico podem ser estabelecidos com as etapas que levam ao descobrimento da identidade do objeto que se encontra oculto no interior da caixa, como procuraremos demonstrar.

\section{Atividade Proposta}

A proposta aqui apresentada se baseia na velha brincadeira da adivinhação. O professor leva uma caixa completamente fechada, contendo um objeto em seu interior. Ele então apresenta as "regras da brincadeira":

1. Dentro da caixa existe um objeto que apenas o professor tem conhecimento e vocês (alunos) tentarão descobrir que objeto é esse.

2. Cada aluno (seguindo, por exemplo, a distribuição das cadeiras) pode fazer apenas uma pergunta. A resposta deverá ser apenas SIM ou NÃO.

3. O aluno poderá substituir a pergunta por uma tentativa de adivinhar qual é o objeto.

4. É conveniente informar aos alunos que as respostas podem não ser muito precisas, isto é, o sim ou o não nada mais é do que uma classificação.

A atividade é iniciada e, após algumas perguntas, notase que o número de possibilidade já foi sensivelmente reduzido. Pode-se então informar aos alunos que muitos experimentos em ciência são realizados de forma muito parecida. Isto é, um (ou vários) experimento(s) é (são) planejado(s) e executado(s) com a finalidade de responder a alguma(s) questão(ões) fundamental(is). Por exemplo, Thomson desenvolveu um elaborado conjunto de experimentos para determinar se aquela partícula recém descoberta, o elétron, tinha carga e massa.

Simbolicamente, na atividade da descoberta da identidade do objeto colocado no interior da caixa, as perguntas representam os experimentos. Os experimentos vão se tornando cada vez mais refinados, à medida que um resultado anterior é obtido. Da mesma forma, as perguntas formuladas vão se aperfeiçoando pelo uso das respostas prévias. A formulação de novas hipóteses e o abandono de outras transcorre ao longo dos experimentos e da atividade com a caixa fechada.

\section{Descrição dos ensaios}

Os dados apresentados e comentados em seguida representam alguns resultados obtidos ao se aplicar em classe a atividade proposta.

$\mathrm{Na}$ Tabela 1 encontram-se alguns dos objetos que foram colocados no interior da caixa, e o número de perguntas que foram formuladas por cada turma, até a descoberta da identidade do objeto.

Tabela 1. Objeto colocado no interior da caixa e o número total de perguntas que foram formuladas até a descoberta da sua identidade.

\begin{tabular}{|l|l|}
\hline Objeto & Número de perguntas \\
\hline Refrigerante (lata de alumínio) & 7 \\
\hline Refrigerante (lata de alumínio)* & 50 \\
\hline Disquete & 12 \\
\hline Filme fotográfico & 65 \\
\hline Filme fotográfico* & 70 \\
\hline Cartão telefônico & 55 \\
\hline
\end{tabular}

* O objeto foi repetido em turmas diferentes

Alguns comentários gerais podem ser feitos em relação ao número de perguntas efetuadas e que resultaram na descoberta da identidade do objeto. Por exemplo, em relação ao refrigerante, a diferença entre o número de perguntas (7 e 50) se deveu fundamentalmente às duas perguntas iniciais. No da turma que encontrou a resposta 
com um total de 7 perguntas, as perguntas iniciais foram:

1. "o objeto é comestível?"

2. “o objeto é líquido?"

Estas duas perguntas acabaram reduzindo muito o universo inicial de possibilidades. Geralmente o refrigerante e o filme fotográfico não são facilmente descobertos, conforme mostram os outros resultados. No entanto, certas perguntas chaves podem fazer as perguntas subseqüentes convergirem rapidamente para a resposta. No caso do filme fotográfico e do disquete, muitas perguntas equivalentes foram formuladas, tais como:

“ele possui partes móveis?"

"é um objeto que depende de outro para funcionar?"

"é usado para registrar informações?"

No caso do disquete, o número de perguntas que conduziram a sua descoberta foi relativamente pequeno, fundamentalmente, por dois motivos. O primeiro é que um disquete é um objeto muito comum aos estudantes, e o segundo, pode-se atribuir ao fato de que o objeto era relativamente óbvio ao grupo, pois este desafio foi levado aos alunos do curso de Engenharia de Computação.

Nota-se que sempre o objeto é descoberto, sem que nenhuma pista seja dada, demonstrando a capacidade dedutiva da mente humana. O momento da descoberta acaba se tornado um momento de celebração do grupo, sendo comum que o aluno que acerta a identidade do objeto receber aplausos. Sugere-se então que o momento seja aproveitado para comentar que todos participaram da descoberta, pois o primeiro a fazer a pergunta tinha remotas chances de acertar, mas contribuiu para eliminar inúmeras possibilidades. Este é o momento apropriado para estabelecer o paralelo com o método científico, pois a turma inteira participou da atividade. Por exemplo, podese mencionar (superficialmente nesta aula) que o modelo atômico atual foi uma evolução que envolveu hipóteses e experimentações, começando pela concepção dos antigos filósofos gregos, passando entre outros pesquisadores por: Dalton, Crockes, Thomson, Millikan, Rutherford, Planck, Einstein, Bohr, Schrödinger, e Heisenberg. A contribuição de cada um deles foi usada sucessivamente para aprimorar o conhecimento sobre uma entidade que não podemos "ver".

Outro exemplo que pode ser utilizado é o da determinação da constituição química das moléculas, que envolveu grandes nomes, como Lavoisier, Dalton, Gay-Lussac,
Avogadro e Canizzaro. Neste exemplo é interessante informar aos alunos que Dalton considerava que a molécula de água era $\mathrm{HO}$ e, que refutava, com bons argumentos, as considerações de Gay-Lussac, que propunha que a água poderia ter a composição que conhecemos hoje [3].

\section{Conclusão}

Alguns aspectos do método científicos aqui apresentados através de um jogo de adivinhação, permitem uma grande integração entre os alunos e o professor. $\mathrm{O}$ potencial dedutivo da mente humana usada no jogo de adivinhação e nos avanços da ciência podem ser relacionados. Com o desenvolvimento desta atividade uma grande expectativa é gerada em torno das aulas seguintes, que dentro do possível podem ser desenvolvidas considerando as hipóteses, os experimentos e os modelos que conduziram ao nosso conhecimento atual da química.

Referências Bibliográficas

1. Lewis, G. N.; Randall, M., "Thermodynamics”; 2nd Edition, McGraw-Hill Book Company, New York, 1961.

2. Atkins, P.; Jones, L., "Chemistry - Molecules, Matter, and Change"; W.H. Freeman and Company, New York, 1997, p 5.

3. Mahan, B.H., "Química - Um curso Universitário"; 2a Edição, Edgard Blücher Ltda., São Paulo, 1972, p 5 . 